\title{
C201 動圧軸受の使用による長期使用可能な血液ポンプの開発
}

Development of blood pumps for a long-term use by hydrodynamic bearings.

\section{O正 築谷朋典（国循）巽 英介（国循）妙中義之（国循）}

Tomonori TSUKIYA, National Cerebral \& Cardiovascular Center, 5-7-1 Fujishirodai, Suita, Osaka

Eisuke TATSUMI, National Cerebral \& Cardiovascular Center

Yoshiyuki TAENAKA, National Cerebral \& Cardiovascular Center

Key words: Pumps, Impellers, Blood, Hydrodynamic Bearing

\section{1. 緒言}

心不全治療における非薬物療法の一つとして, 血液ポンプを 用いた機械的補助循環が広く用いられるようになった。最大 の理由は, 血液ポンプを中心とする機器の性能が飛躍的に向 上し，耐久性，信頼性が著しく向上したことである，血液ポ ンプの研究開発は心臓血管外科の黎明期でもある 1950 年代 後半にまで遡る. 当時は心臟を切除して左心・右心の $2 つ の$ 血液ポンプで代行する完全人工心臓 (Total Artificial Heart : $\mathrm{TAH})$ の開発が目的であったが，その後，心臓のポンプ機能 を補助・代替する補助人工心臓 (Ventricular Assist Device : VAD) の開発が中心となっていった。これらのデバイスは心 臓移植までのつなぎとして使用される前提で開発されてき たが，それでも数年間メンテナンスフリーで使用できる耐久 性が必要である。一方, 体内植込みに有利な超小型連続流ポ

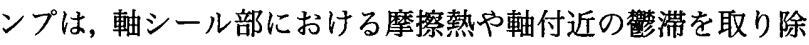
くという大きな課題を抱えていた。この課題を解決すべく, 非接触軸受を有する血液ポンプが実用化され始めた(1).

我々は，高い耐久性を有する血液ポンプを中心とする治療技 術の拡充を目指して臨床ニーズに応じた様々な形態の血液 ポンプの開発を行ってきた。ここでは，非接触で羽根車を支

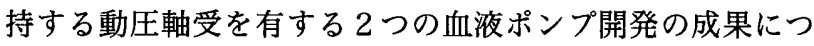
いて述べる。

\section{2. 体内植込み型補助人工心炡用軸流ポンプ}

体内埋込型補助人工心臓は, 主に左心室のポンプ機能を補 助するために左心室から血液を吸い込み，ポンプによって昇 圧後大動脈に吐き出す形式をとる. 血液ポンプは胸腔あるい は腹壁内に留置し, ポンプ駆動用ケーブルが皮膚を貫通して 体外のコントローラに接続される（図 1).

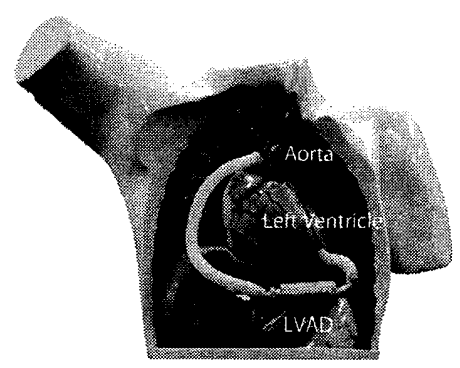

Fig.1 Implantable Ventricular Assist Device

米国では, 軸流型の血液ポンプ (HeartMate II®, Thoratec, US) が小型化, 耐久性の向上, 感染率の低下等多くの面で従来の 拍動型ポンプに比べて優れていることが実証され, 現在では 年間 3000 例以上使用されている(2).このポンプのインペラに
は永久磁石が埋め込まれ，DC ブラシレスモータの回転子を 兼ねているが，両端をピボットで支持しているために機械的 接触が残り，このピボット部での血栓形成例も報告されてい る(3). 我々は, 高い抗血栓性を持つポンプの実現を目的とし て, 動圧軸受を有する軸流ポンプの開発を行った. 開発した 軸流ポンプは，全ての血液接触面がチタン合金製であり，長 さ $75 \mathrm{~mm}$, 直径 $29 \mathrm{~mm}$, ポンプ本体の重量は $150 \mathrm{~g}$ である. インペラには永久磁石が内包され，血液流路外部に設置され たコイルにより駆動される.インペラは円筒状のボディに羽 根を有しており，図 2 に示すように，中心を貫通する軸との 隙間において動圧軸受を構成している. 補助人工心臓は患者 の状態に応じて補助すべき流量ならびに発生する圧力が異 なるが, 平均的な動作点として流量 $5.0 \mathrm{~L} / \mathrm{min}$, 揚程 100 $\mathrm{mmHg}$ を設定しており, 本ポンプは約 $9000 \mathrm{rpm}$ においてこ の条件を達成可能である。この時のモー夕消費電力は約 $5 \mathrm{~W}$

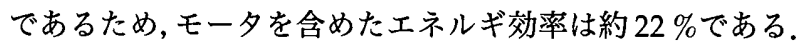
ポンプの圧力特性を図 3 に示す，軸流ポンプではあるが，圧 力特性には右上がり不安定は存在していない. 抗血栓性, 血 球破壊量を含む生体適合性評価は実験動物により実施して いる. 実験動物の胸腔内に血液ポンプを植込み, 実使用条件 で3か月間連続運転を合計 8 例実施した. 動物実験では良好 な抗血栓性と臨床的に許容できる範囲の血球破壊量である ことを確認している。運転中は生体心の拍動により流量が 2-7 L/min の範囲で変動したが, 実験終了後のポンプを改札 してもインペラが接触した形跡は見られず, 動圧軸受は安定 して動作していた
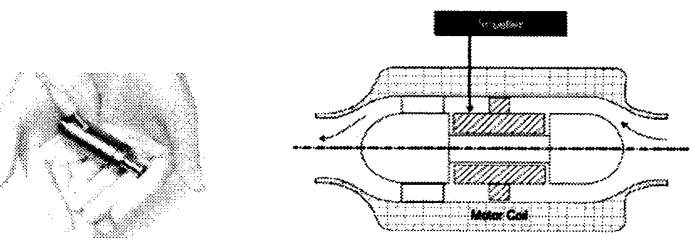

Fig.2 Structure of the axial flow pump

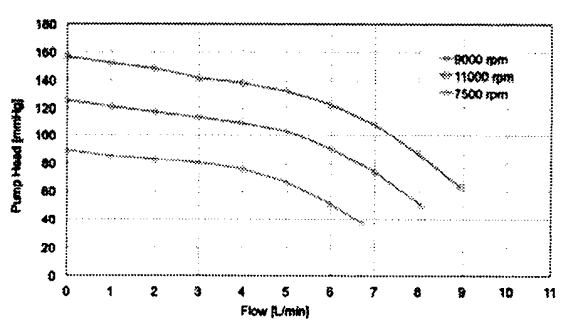

Fig.3 Hydrodynamic Characteristics of the axial flow pump 


\section{3. 体外設酉型呼吸熘環補助用速心ポンプ}

血液ポンプを用いた循環補助法のうち，緊急に循環補助を 必要とする患者には, 救命と血行動態の安定を図る目的で血 液ポンプと人工肺を組み合わせた心肺補助装置の使用が検 討される(4)。このような目的に使用する血液ポンプには現在 専用機種はなく，開心術で用いられる体外循環を想定した 6 時間までの使用が認められた機種が, 必要であればポンプを 交換しつつ使用されている。しかしながら，ポンプ交換の際 には補助を一時的に中断し強力な抗凝固療法を多用すると いったリスクに加え，複数のポンプを使用することで患者・ 病院にとっても経済的負担が大きいという問題が存在する. 抗血栓性に優れ, 数日から一か月程度まで連続使用可能な血 液ポンプが実現できれば, 血液ポンプと人工肺の組み合わせ により呼吸循環補助を行う Extracorporeal Membrane

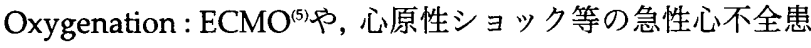
者に対する循環補助法に用いることが可能である. 血液ポン プの抗血栓性が優れていれば抗凝固療法を最小化すること が可能となり, 出血や炎症反応といったデバイスの使用に伴 う合併症を抑制する効果が期待できる.

我々が開発を行った遠心ポンプは，図 4 に示すように，駆動 用永久磁石内包部とインペラ入口部の 2 か所（図中点線部） で軸方向の動圧軸受を構成する新しい形状のインペラを有 する.このインペラはディスポーザブルでありながら非接触 で回転可能である.開発したポンプはポリカーボネート製の ポンプヘッドと駆動モータから構成され，モー夕側に設置さ れた永久磁石とインペラ内部の永久磁石による磁気カップ リングによって駆動される。モータを含めたポンプ部は軸方 向長さ $123 \mathrm{~mm}$, 直径 $60 \mathrm{~mm}$ であり, 重量は $630 \mathrm{~g}$ である.

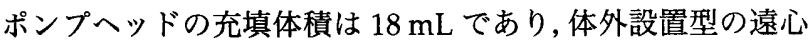
ポンプとしては現時点で最も小さい. 心肺補助装置用血液ポ ンプの動作点は回路構成に大きく依存するため設計点の決 定には注意を要するが, 本ポンプは比較的高い揚程にも対応 できるよう, 流量 $5.0 \mathrm{~L} / \mathrm{min}$, 揚程 $400 \mathrm{mmHg}$ を動作点と

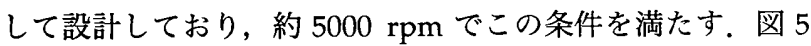
に遠心ポンプのポンプ特性を示す.インペラはシュラウドを 持つ完全二次元羽根である. 磁石部を内包している部分には 中心に孔が設けられており,インペラを出た血液の一部がポ ンプ底部を洗い流し，血栓を防止する効果を狙つている。 こ の遠心ポンプについても，動物実験によって生体適合性の検 討を行っており，人工肺と組み合わせた呼吸循環補助システ ムとして, 連続 30 日間の運転を安定して行うことに成功し ており, ポンプの安定した動作, 優れた抗血栓性を実証する ことに成功した. また, 動圧軸受を構成する狭い隙間での血 球破壊についても許容範囲内であった。

このポンプは人工肺を使用しない簡易左心バイパス用ポン プとしても有用であると考えられるが, 左心バイパスに用い る際は回路が短く揚程が低くなるためにより低い回転数で の運転となる．そのために動圧軸受の安定性に関して注意が 必要であると考えられる.これまでの検討で揚程 $100 \mathrm{mmHg}$ 程度の運転条件でも安定した動圧浮上の状態が実現できて おり,このとき血球破壊量も問題ないことが実験的に確かめ られている. 現在, 1 ケ月運転の耐久性・安全性を動物実験 で確認中である。

\section{4. 結語}

非接触軸受である動圧軸受は, 抗血栓性に優れた血液ポン プを実現するための重要な要素である，著者等は近年著しい 発展を遂げてきた機械的補助循環法による治療技術のさら なる拡充を目指し, 本研究で行ったような動圧軸受を応用し た血液ポンプならびにそのシステムを開発している. 血液ポ ンプの大きな特徵として, 動作点があらかじめ決定できず幅 広い流量と回転数の下で運転する可能性があるため, 動圧軸 受が接触せず安定に動作する条件について十分検討してお く必要がある.また, 動圧軸受を構成する狭い流路は高いせ ん断応力による血球破壊の可能性があることに留意すべき であると考える。
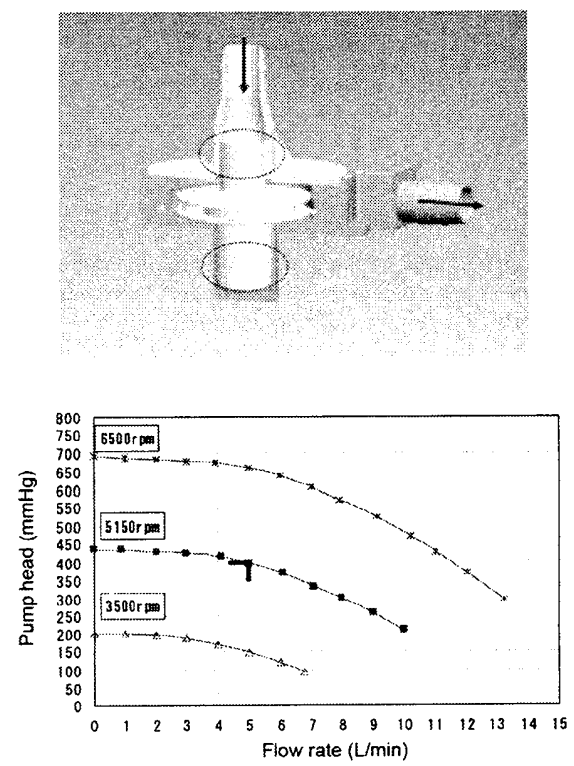

Fig.4 Cross Section of the Extracorporeal Centrifugal Pump

Fig.5 Hydrodynamic Characteristics of the Extracorporeal Centrifugal Pump

\section{引用文献}

(1) Kormos RL, Miller LW, Mechanical Circulatory Support : A Companion to Braunwald's Heart Disease, Elsevier, 2012.

(2) Kirklin JK, et al., Sixth INTERMACS annual report: A 10,000-patient database, 33, 555-564, 2014.

(3) Meyer AL, et al., Thrombus formation in a HeartMate II left ventricular assist device, Journal of Thoracic and Cardiovascular Surgery, Vol.135, No.1, pp.203-204, 2008.

(4) Extracorporeal Life Support Organization, General Guidelines for all ECLS Cases, 2009.

(5) Sinard JM, Bartlett RH, Extracorporeal membrane oxygenation (ECMO): prolonged bedside cardiopulmonary bypass, Perfusion, Vol.5, pp.239-249, 1990. 